\title{
Characterization of the ion-amorphization process and thermal annealing effects on third generation $\mathrm{SiC}$ fibers and $6 \mathrm{H}-\mathrm{SiC}$
}

\author{
Juan Huguet-Garcia $^{1 *}$, Aurélien Jankowiak ${ }^{1}$, Sandrine Miro ${ }^{2}$, Renaud Podor ${ }^{3}$, Estelle Meslin ${ }^{4}$, Lionel Thomé ${ }^{5}$, \\ Yves Serruys $^{2}$, and Jean-Marc Costantini ${ }^{1}$ \\ ${ }^{1}$ CEA, DEN, Service de Recherches Métallurgiques Appliquées, 91191 Gif-sur-Yvette, France \\ 2 CEA, DEN, Service de Recherches en Métallurgie Physique, Laboratoire JANNUS, 91191 Gif-sur-Yvette, France \\ ${ }^{3}$ ICSM-UMR5257 CEA/CNRS/UM2/ENSCM, Site de Marcoule, bâtiment 426, BP 17171, 30207 Bagnols-sur-Cèze, France \\ ${ }^{4}$ CEA, DEN, Service de Recherches en Métallurgie Physique, 91191 Gif-sur-Yvette, France \\ ${ }^{5}$ CSNSM, CNRS-IN2P3, Université Paris-sud, 91405 Orsay, France
}

Received: 11 June 2015 / Received in final form: 14 September 2015 / Accepted: 24 September 2015

Published online: 09 december 2015

\begin{abstract}
The objective of the present work is to study the irradiation effects on third generation SiC fibers which fulfill the minimum requisites for nuclear applications, i.e. Hi-Nicalon type S, hereafter HNS, and Tyranno SA3, hereafter TSA3. With this purpose, these fibers have been ion-irradiated with $4 \mathrm{MeV} \mathrm{Au}$ ions at room temperature and increasing fluences. Irradiation effects have been characterized in terms of micro-Raman Spectroscopy and Transmission Electron Microscopy and compared to the response of the as-irradiated model material, i.e. $6 \mathrm{H}-\mathrm{SiC}$ single crystals. It is reported that ion-irradiation induces amorphization in $\mathrm{SiC}$ fibers. Ionamorphization kinetics between these fibers and $6 \mathrm{H}-\mathrm{SiC}$ single crystals are similar despite their different microstructures and polytypes with a critical amorphization dose of $\sim 3 \times 10^{14} \mathrm{~cm}^{-2}(\sim 0.6 \mathrm{dpa})$ at room temperature. Also, thermally annealing-induced cracking is studied via in situ Environmental Scanning Electron Microscopy. The temperatures at which the first cracks appear as well as the crack density growth rate increase with increasing heating rates. The activation energy of the cracking process yields $1.05 \mathrm{eV}$ in agreement with recrystallization activation energies of ion-amorphized samples.
\end{abstract}

\section{Introduction}

Future nuclear applications include the deployment of the so-called Generation IV fission and fusion reactors, which are devised to operate at higher temperatures and to higher exposition doses than nowadays nuclear reactors. One of the critical issues to the success of future nuclear applications is to develop high performance structural materials with good thermal and radiation stability, neutron transparency and chemical compatibility [1].

Structural materials for nuclear applications are exposed to high temperatures, aqueous corrosive environments and severe mechanical loadings while exposed to neutron and ion irradiation. Its exposure to incident energetic particles displaces numerous atoms from the lattice sites inducing material degradation. Such degradation is the main threat to the safe operation of core internal structures and is manifested in several forms: radiation hardening and embrittlement, phase instabilities from radiation-induced

\footnotetext{
*e-mail: juan.huguet-garcia@cea.fr
}

or enhanced precipitation, irradiation creep and volumetric swelling [2]. As can be observed in Figure 1, nominal temperatures and displacement doses can reach up to $1100^{\circ} \mathrm{C}$ and $200 \mathrm{dpa}$ depending on the nuclear reactor design. As a consequence, conventional nuclear materials, mostly metallic alloys, do not meet the requirements to operate neither under nominal nor accidental conditions.

Nuclear grade Silicon Carbide based composites - made of third generation $\mathrm{SiC}$ fibers densified via chemical vapor infiltration (CVI) with a $\mathrm{SiC}$ matrix; $\mathrm{SiC}_{\mathrm{f}} / \mathrm{SiC}_{\mathrm{m}}-$ are among the most promising structural materials for fission and fusion future nuclear applications [3]. However, several remaining uncertainties place $\mathrm{SiC}_{\mathrm{f}} / \mathrm{SiC}_{\mathrm{m}}$ in a position that requires further research and development, notably the radiation behavior of the fiber reinforcement which is crucial for the composite radiation stability.

The objective of the present work is to study the irradiation effects on third generation $\mathrm{SiC}$ fibers which fulfill the minimum requisites for nuclear applications, i.e. Hi-Nicalon type S, hereafter HNS, and Tyranno SA3, hereafter TSA3. With this purpose, these fibers have been ion-irradiated at room temperature to different doses under 


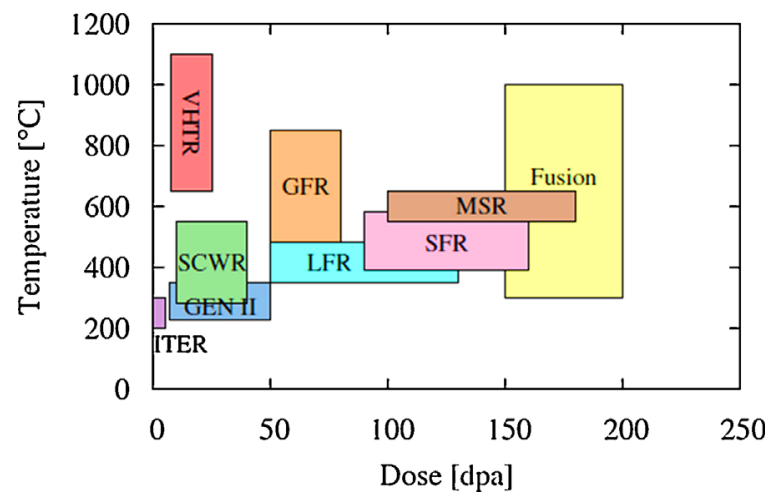

Fig. 1. Nominal operating temperatures and displacement doses for structural materials in different nuclear applications. The acronyms are defined in the Nomenclature section (adapted from Ref. [2]).

elastic energy loss regimes to simulate neutron damage. The irradiation effects have been characterized in terms of micro-Raman Spectroscopy ( $\mu \mathrm{RS}$ ), Transmission Electron Microscopy (TEM) and Environmental Scanning Electron Microscopy (E-SEM) and compared to the response of the as-irradiated model material, i.e. $6 \mathrm{H}-\mathrm{SiC}$ single crystals.

\section{Materials and methods}

\section{$2.16 \mathrm{H}-\mathrm{SiC}$ single crystals and third generation SiC fibers}

$6 \mathrm{H}-\mathrm{SiC}$ single crystals of $246 \mu \mathrm{m}$ thickness were machined from $\mathrm{N}$-doped (0001)-oriented $6 \mathrm{H}-\mathrm{SiC}$ single crystal wafers grown by CREE Research using a modified Lely method. Crystals were of n-type with a net doping density $\left(\mathrm{n}_{\mathrm{D}}-\mathrm{n}_{\mathrm{A}}\right)$ of $10^{17} \mathrm{~cm}^{-3}$. All samples were polished to achieve a microelectronics "epiready" quality.

Main characteristics of HNS and TSA3 fibers are summarized in Table 1. Figure 2 shows TEM images of the microstructures of both fibers. Both fibers consist in highly
Table 1. Main characteristics of third generation $\mathrm{SiC}$ fibers.

\begin{tabular}{lll}
\hline Fiber & Tyranno SA3 & Hi-Nicalon type S \\
\hline Producer $[6]$ & Ube Industries & Nippon Carbon \\
Diameter $(\mu \mathrm{m})[6]$ & 7.5 & 12 \\
Density $\left(\mathrm{g} \mathrm{cm}^{-3}\right)[6]$ & 3.1 & 3.05 \\
C/Si ratio $[7]$ & $1.03-1.2$ & 1.07 \\
Composition $[6]$ & $68 \mathrm{Si}+32 \mathrm{C}$ & $69 \mathrm{Si}+31 \mathrm{C}+0.2 \mathrm{O}$ \\
Grain Size $(\mathrm{nm})^{\mathrm{b}}[5]$ & $+0.6 \mathrm{Al}$ & \\
\hline
\end{tabular}

${ }^{a}$ Values correspond to the edge and core of the fiber respectively. ${ }^{\mathrm{b}}$ Min. and max. Feret diameters.

faulted 3C-SiC grains and intergranular pockets of turbostratic C visible as white zones in Figure 2. Stacking Faults (SFs) in $\mathrm{SiC}$ grains are clearly observed for both fibers as striped patterns inside the grains. Stacking fault linear density yields $0.29 \pm 0.1 \mathrm{~nm}^{-1}$ for HNS fibers and $0.18 \pm 0.1 \mathrm{~nm}^{-1}$ for TSA3 fibers. It has been determined by counting the number of stripes per unit length in the perpendicular direction using ImageJ [4] image analysis software. Also, mean maximum and minimum Feret diameters - which correspond to the shortest and the longest distances between any two points along the grain boundary (GB) - were determined. These values yield, respectively, 26 and $36 \mathrm{~nm}$ for the HNS fibers and 141 and $210 \mathrm{~nm}$ for the TSA3 fibers [5].

\subsection{Ion-irradiation}

Different $6 \mathrm{H}-\mathrm{SiC}$ single crystals and $\mathrm{SiC}$ fibers were irradiated at room temperature (RT) with $4 \mathrm{MeV} \mathrm{Au}^{2+}$ to $5 \times 10^{12}, 10^{13}, 5 \times 10^{13}, 10^{14}, 2 \times 10^{14}, 3 \times 10^{14}, 10^{15} \mathrm{~cm}^{-2}$ at JANNUS-Orsay facility and to $2 \times 10^{15} \mathrm{~cm}^{-2}$ at JANNUS-Saclay facility [8]. To evaluate the irradiation

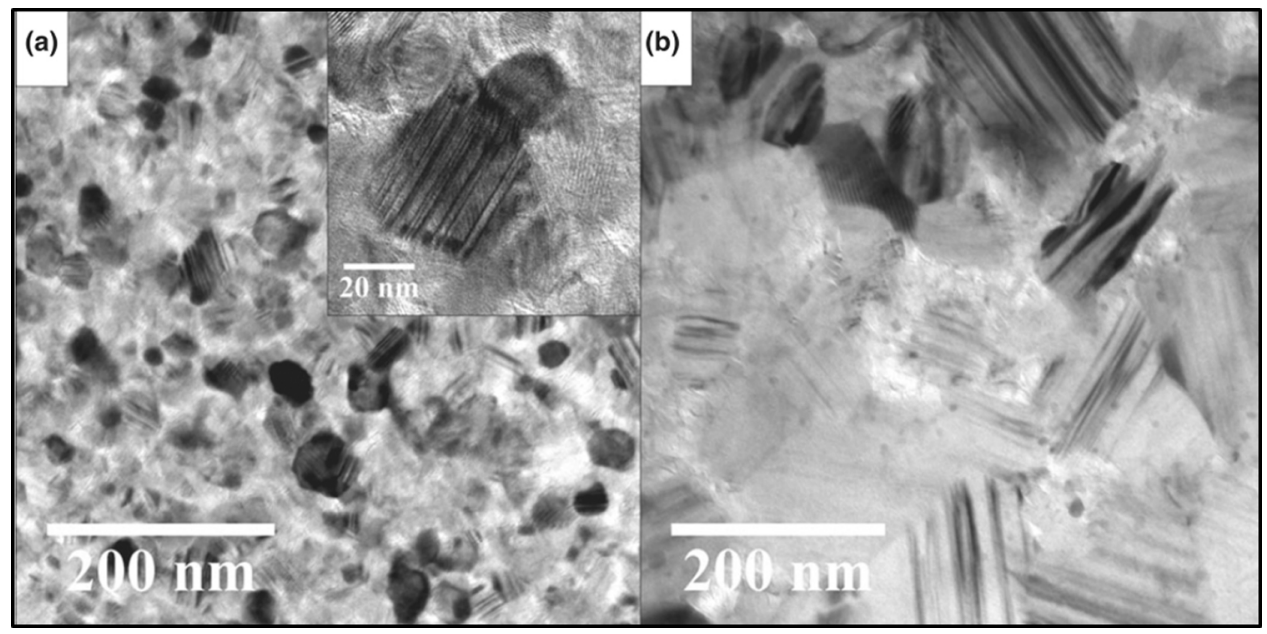

Fig. 2. TEM images of the as-received (a) HNS and (b) TSA3 fibers. Stripped patterns inside the grains indicate the high density of stacking faults in both samples (reproduced from Ref. [5]). 


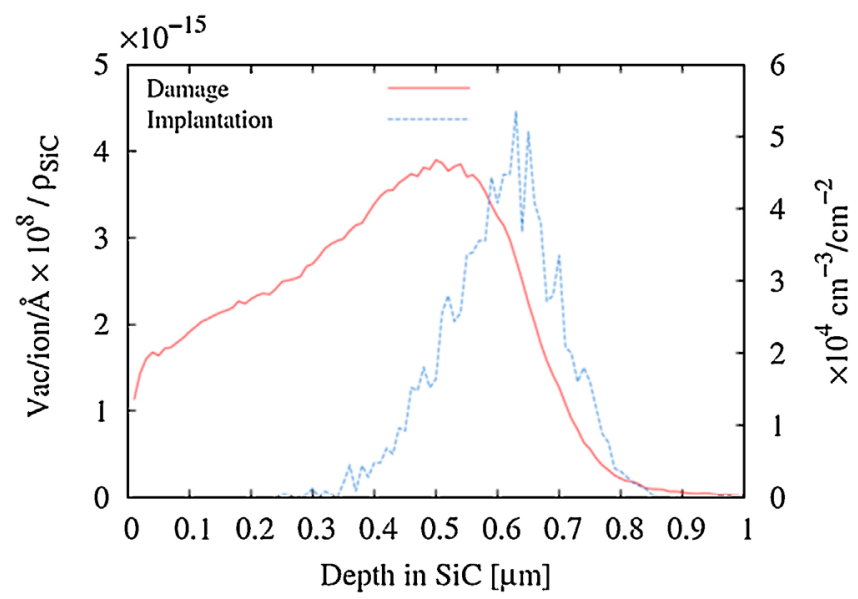

Fig. 3. Damage and implantation profiles for $4 \mathrm{MeV} \mathrm{Au}$ in $\mathrm{SiC}$. Fluence-dpa estimation can be obtained by direct multiplication of the $y$-axis per the ion fluence.

damage, ion-fluences have been converted to dpa with equation (1):

$$
d p a=\frac{\frac{V a c}{\text { ion } \mathrm{A}} \times 10^{8}}{\rho_{\text {SiC }}\left[\text { atoms } \mathrm{cm}^{-3}\right]} \times \varphi\left[\text { ions } \mathrm{cm}^{-2}\right]
$$

where $\varphi$ is the ion fluence, $\rho_{\mathrm{SiC}}$ the theoretical density of $\mathrm{SiC}$ $\left(3.21 \mathrm{~g} \mathrm{~cm}^{-3}\right)$ and $\frac{V a c}{i o n \AA}$ the vacancy per ion ratio given by SRIM-2010 calculations [9]. Figure 3 shows the vacancy per ion ratio and the implantation profiles as a function of the $\mathrm{SiC}$ depth. SRIM calculations have been performed with full damage cascades. Threshold displacement energies for $\mathrm{C}$ and Si sublattices were set to 20 and $35 \mathrm{eV}$ respectively [10].

\subsection{Micro-Raman Spectroscopy ( $\mu$ RS)}

Irradiated samples were characterized at JANNUS-Saclay facility by surface $\mu \mathrm{RS}$ at RT using an Invia Reflex Renishaw (Renishaw plc, Gloucestershire, UK) spectrometer. The $532 \mathrm{~nm}$ line of a frequency-doubled Nd-YAG laser was focused on a $0.5 \mu \mathrm{m}^{2}$ spot and collected through a $100 \times$ objective. The laser output power was kept around $2 \mathrm{~mW}$ to avoid sample heating.

\subsection{Transmission (TEM) and Environmental Scanning Electron Microscopy (E-SEM)}

Thin foils for TEM observations were prepared using the Focused Ion Beam (FIB) technique. The specimens were extracted from the samples irradiated to $2 \times 10^{15} \mathrm{~cm}^{-2}$ using a Helios Nanolab 650 (FEI Co., Hillsboro, OR, USA) equipped with electron and $\mathrm{Ga}$ ion beams. The specimen preparation procedure is described elsewhere [5]. TEM observations were conducted in a conventional CM20 TWIN-FEI (Philips, Amsterdam, Netherlands) operated at $200 \mathrm{kV}$ equipped with a LaB6 crystal as electron source and a Gatan (Gatan Inc, Warrendale, PA, USA) heating specimen holder $\left(25-1000^{\circ} \mathrm{C}\right)$ with manual temperature control. The CCD camera used to take pictures is a Gatan Orius 200.

The E-SEM observation was conducted in a FEI QUANTA 200 ESEM FEG equipped with a heating plate $\left(25-1500{ }^{\circ} \mathrm{C}\right)$, operated at $30 \mathrm{kV}$. Precise sample temperature measurement is ensured by a homemade sample holder containing a Pt-Pt-Rh10 thermocouple [11]. $\mathrm{H}_{2} \mathrm{O}$ pressure was kept constant at $120 \mathrm{~Pa}$. The $6 \mathrm{H}-\mathrm{SiC}$ samples were quickly heated up to $900^{\circ} \mathrm{C}$ to then set the heating rate to values ranging from 1 to $30^{\circ} \mathrm{C} / \mathrm{min}$ for each test.

\section{Results and discussion}

\subsection{Third generation SiC fibers microstructure and Raman spectra}

$\mu \mathrm{RS}$ is a powerful characterization technique based on the inelastic scattering of light due to its interaction with the material atomic bonds and the electron cloud providing a chemical fingerprint of the analyzed material. $\mathrm{SiC}$ is known to have numerous stable stoichiometric solid crystalline phases, so-called polytypes, the cubic (3C-SiC) and the hexagonal $(6 \mathrm{H}-\mathrm{SiC})$ being the most common ones [12]. Raman peak parameters such as intensity, bandwidth and wavenumber provide useful information related to the phase distribution and chemical bonding of $\mathrm{SiC}$ and $\mathrm{SiC}$ fibers [13]. Table 2 gathers the characteristic Raman peak wavenumber for $3 \mathrm{C}$ - and $6 \mathrm{H}-\mathrm{SiC}$ polytypes.

Figure 4 shows the collected Raman spectra for the asreceived samples. For the $6 \mathrm{H}-\mathrm{SiC}$ spectrum, grouptheoretical analysis indicates that the Raman-active modes of the wurtzite structure $\left(\mathrm{C}_{6 \mathrm{v}}\right.$ symmetry for hexagonal polytypes) are the $\mathrm{A}_{1}, \mathrm{E}_{1}$ and $\mathrm{E}_{2}$ modes. In turn, $\mathrm{A}_{1}$ and $\mathrm{E}_{1}$ phonon modes are split into longitudinal (LO) and transverse (TO) optical modes. Also, the high quality of the sample allows the observation of second order Raman bands as several weaker peaks located at $500 \mathrm{~cm}^{-1}$ and between $1400-1850 \mathrm{~cm}^{-1}$.

Raman spectra collected from as-received TSA3 and HNS fibers differ notably from the single crystal one. Their polycrystalline microstructure and the intergranular free $\mathrm{C}$ shown in Figure 2 induce the apparition of several peaks related to their chemical fingerprint. Peaks located between the $700 \mathrm{~cm}^{-1}$ and $1000 \mathrm{~cm}^{-1}$ are related to the cubic $\mathrm{SiC}$ polytype. Satellite peaks around $766 \mathrm{~cm}^{-1}$ are attributed to disordered $\mathrm{SiC}$ consisting of a combination of simple polytype domains and nearly periodically distributed stacking faults $[13,14]$. This explanation is consistent with the high SF density observed in Figure 2.

High-intensity peaks located between $1200 \mathrm{~cm}^{-1}$ and $1800 \mathrm{~cm}^{-1}$ are attributed to the intergranular free $\mathrm{C}$ despite the little free $\mathrm{C}$ content of both fibers. The high contribution of these peaks to the spectra is due to the high Raman crosssection of $\mathrm{C}-\mathrm{C}$ bonds which is up to ten times higher than the $\mathrm{Si}-\mathrm{C}$ bonds [15]. Regarding the $\mathrm{C}$ chemical fingerprint, the $\mathrm{G}$ peak centered around $1581 \mathrm{~cm}^{-1}$ is related to graphitic structures as a result of the $\mathrm{sp}^{2}$ stretching modes of $\mathrm{C}$ bonds and the D peak centered around $1331 \mathrm{~cm}^{-1}$, according to Colomban et al. [13], should be attributed to vibrations 


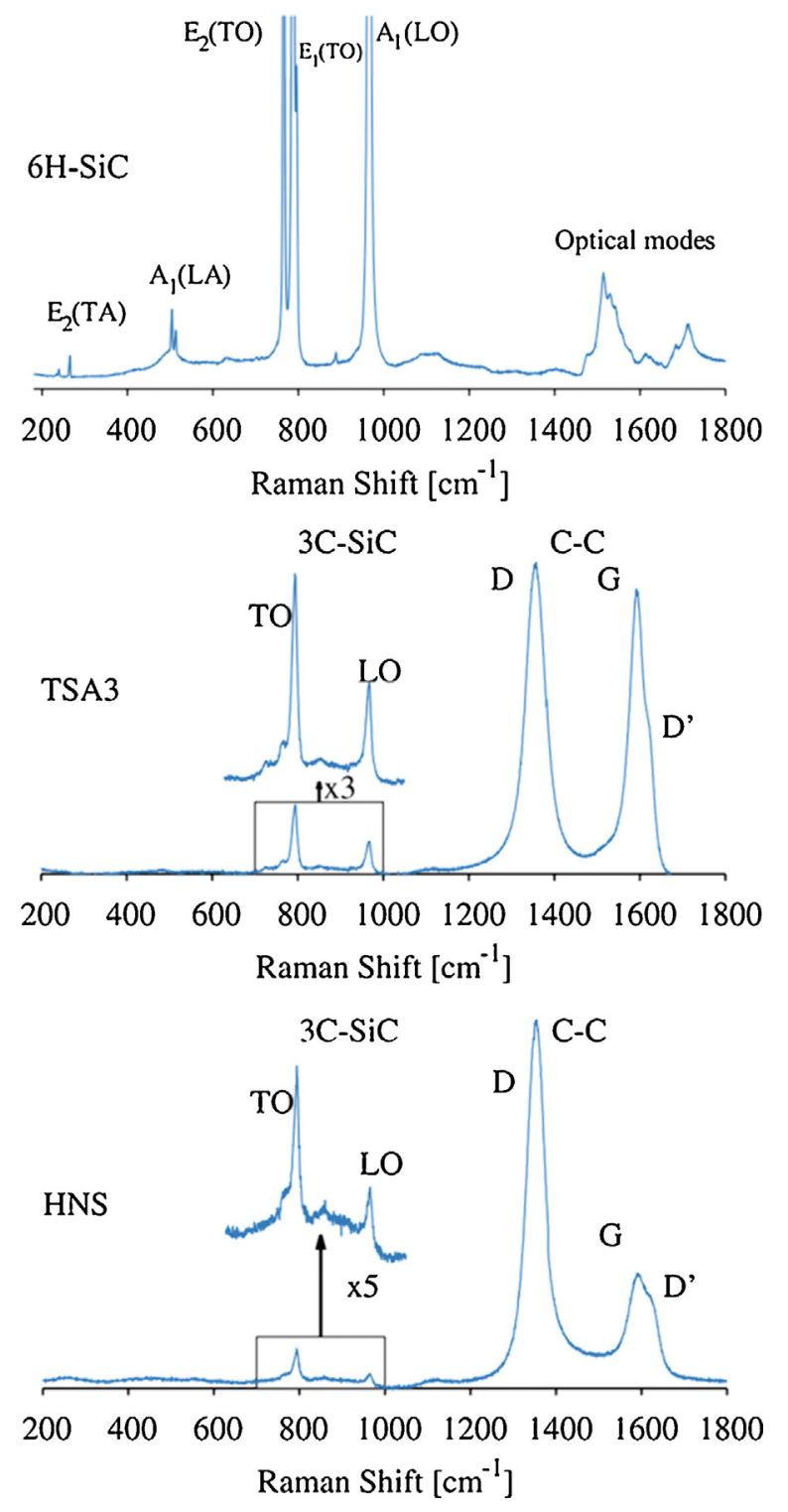

Fig. 4. Surface Raman spectra for as-received $6 \mathrm{H}-\mathrm{SiC}$ single crystal and third generation $\mathrm{SiC}$ fibers (adapted from Ref. [5]).

involving $\mathrm{sp}^{3}-\mathrm{sp}^{2 / 3}$ bonds. Finally, the shouldering appearing on the $\mathrm{G}$ band in both fibers, $\mathrm{D}$ ', results from the folding of the graphite dispersion branch corresponding to $\mathrm{G}$ at $\Gamma$ point.
There is a remarkable difference in the $\mathrm{G}$ peak intensity between TSA3 and HNS fibers. It has been stated that the $\mathrm{G}$ over $\mathrm{D}$ peak intensity ratio is proportional to the in-plane graphitic crystallite size [17]. Therefore, the smaller size of the intergranular free $\mathrm{C}$ pockets of HNS takes account for such difference.

\subsection{Ion-irradiation-induced amorphization}

During service as nuclear structural material, SiC composites will be subjected to neutron and ion-irradiation. When an energetic incident particle elastically interacts with a lattice atom, there is a kinetic energy exchange between them. If this transmitted energy is higher than the threshold displacement energy of the knocked lattice atom, it will be ejected from its equilibrium position giving birth to a Frenkel pair: a vacancy and an interstitial atom. In turn, if the kinetic energy transfer is high enough, the displaced atom may have enough kinetic energy to displace not only one but many atoms of the lattice, which, in turn, will cause other displacement processes giving birth to displacement cascade. The number of surviving defects after the thermal recombination of the displacement cascade may pile up dealing to the degradation of the exposed material [18].

Ion-irradiation has been widely used by the nuclear materials community to simulate neutron damage due to the tunability of the radiation parameters (dose, dose rate, temperature) and the similarity of the defect production in terms of displacement cascade creation [19].

In this work, the samples have been irradiated to increasing fluences at RT with $4 \mathrm{MeV} \mathrm{Au}$ ions in order to simulate neutron damage. Figure 5 shows the evolution of the Raman spectra as a function of the irradiation dose. As can be observed, ion-irradiation induces sequential broadening of the $\mathrm{Si}-\mathrm{C}$ bond related peaks until they combine in a unique low-intensity broad peak. Also, ion-irradiation induces the appearance of new low-intensity broad peaks at $\sim 500 \mathrm{~cm}^{-1}$ and $\sim 1400 \mathrm{~cm}^{-1}$. These changes with dose in the Raman spectra are the consequence of the increasing damage of the crystal lattice and are usually attributed to the dissociation of the $\mathrm{Si}-\mathrm{C}$ bonds and the creation of $\mathrm{Si}-\mathrm{Si}$ and $\mathrm{C}-\mathrm{C}$ homonuclear bonds [20], in agreement with EXAFS [21] or EELS [22] data and theoretical analyses [23]. However, some authors have pointed out that changes

Table 2. Raman shift for 3C- and $6 \mathrm{H}-\mathrm{SiC}$ [16].

\begin{tabular}{|c|c|c|c|c|c|}
\hline \multirow[t]{3}{*}{ Polytype } & \multirow[t]{3}{*}{$\mathrm{X}=\mathrm{q} / \mathrm{qB}$} & \multicolumn{4}{|c|}{ Raman shift $\left[\mathrm{cm}^{-1}\right]$} \\
\hline & & Planar acoustic & Planar optic & Axial acoustic & Axial optic \\
\hline & & TA & TO & LA & LO \\
\hline \multirow[t]{2}{*}{ 3C-SiC } & 0 & - & 796 & - & 972 \\
\hline & 0 & - & 797 & - & 965 \\
\hline \multirow[t]{3}{*}{$6 \mathrm{H}-\mathrm{SiC}$} & $2 / 6$ & 145,150 & 789 & - & - \\
\hline & $4 / 6$ & 236,241 & & 504,514 & 889 \\
\hline & $6 / 6$ & 266 & 767 & - & - \\
\hline
\end{tabular}




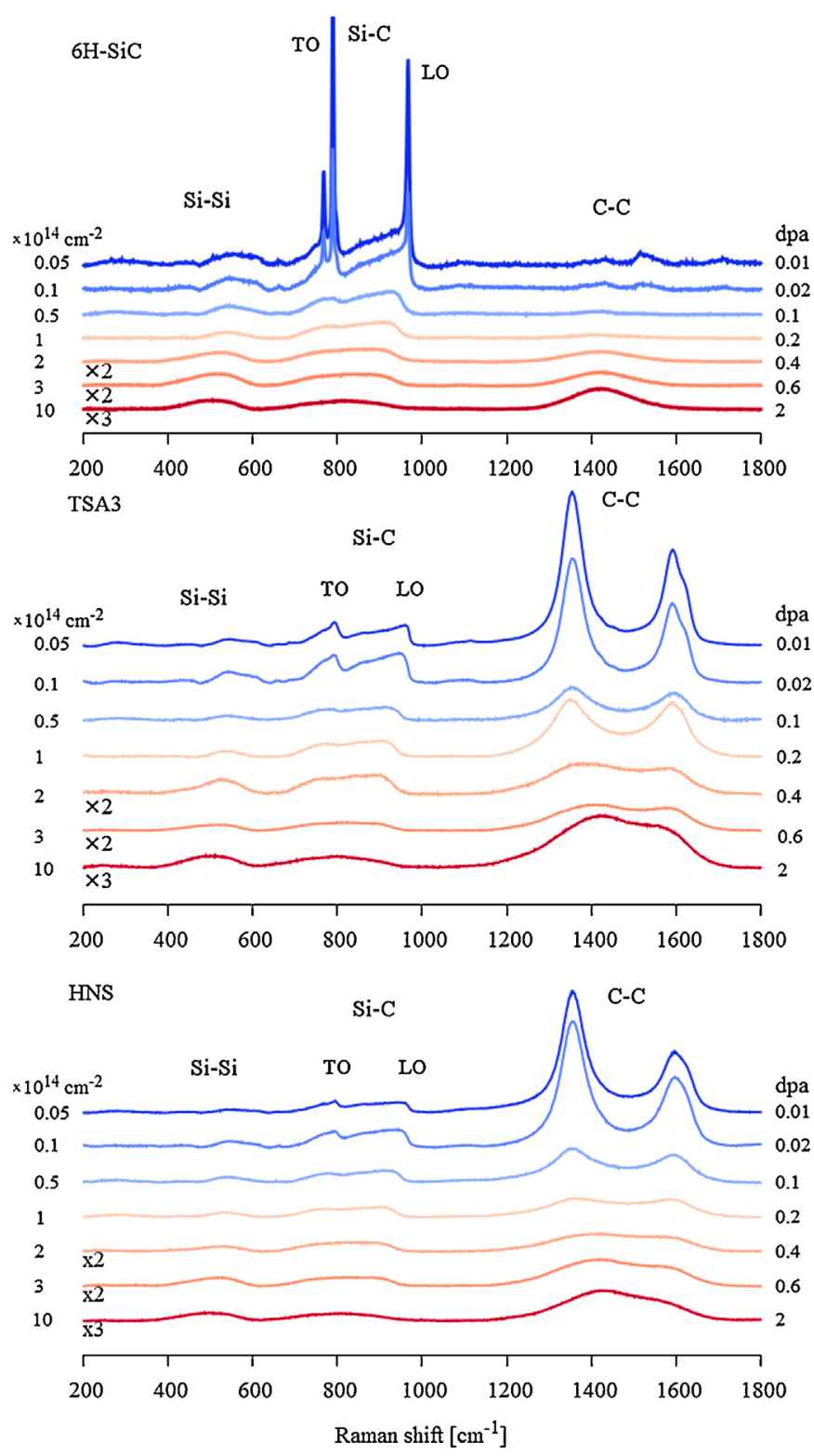

Fig. 5. Surface Raman spectra for ion-irradiated $6 \mathrm{H}-\mathrm{SiC}$ single crystal and third generation $\mathrm{SiC}$ fibers.

in the Raman spectra in $\mathrm{SiC}$ for moderated irradiation damage do not necessarily imply the formation of Si and $\mathrm{C}$ homonuclear bonds. For instance, the abrupt end of the broad band observed near the $950 \mathrm{~cm}^{-1}$ for samples irradiated to $10^{14} \mathrm{~cm}^{-2}$ in Figure 5 can be attributed to a release of the Brillouin zone-center Raman selection rules due to a loss of translation symmetry caused by minor and local damage without amorphization [24]. It is worth to highlight that in $\mathrm{SiC}$ fibers irradiation at low doses increases the intensity of the $\mathrm{Si}-\mathrm{C}$ related peak despite its randomization. As commented, there is a remarkable influence of the free $\mathrm{C}$ in the $\mathrm{SiC}$ fibers Raman spectra due to the high Raman cross-section of $\mathrm{C}-\mathrm{C}$ bonds. Under irradiation, the rupture of these bonds will imply the drop of its cross-section allowing the $\mathrm{SiC}$ Raman signal to emerge over the free $\mathrm{C}$ one. Finally, the spectra show similar low- intensity broad peaks at $\sim 800 \mathrm{~cm}^{-1}$ characteristic of amorphous $\mathrm{SiC}$. As can be observed in Figure 6, complete amorphization of the ion-irradiated layer is confirmed by TEM imaging and electron diffraction of samples irradiated to $4 \mathrm{dpa}\left(2 \times 10^{15} \mathrm{~cm}^{-2}\right)$. SAED patterns of these zones are composed of diffuse concentric rings.

Ion-amorphization kinetics for $6 \mathrm{H}-\mathrm{SiC}$ single crystals has been previously studied by $\mu \mathrm{RS}$ in terms of the total disorder parameter and the chemical disorder. The former is defined as $\left(1-\mathrm{A} / \mathrm{A}_{\text {cryst }}\right)$ corresponding to the total area $\mathrm{A}$ under the principal first-order lines normalized to the value $\mathrm{A}_{\text {cryst }}$ of the crystalline material. The latter is defined as the ratio of $\mathrm{C}-\mathrm{C}$ homonuclear bonds to $\mathrm{Si}-\mathrm{C}$ bonds and denoted as $\chi_{(\mathrm{C}-\mathrm{C})}$, ranging from zero for perfect short-range order to unity for random short-range disorder. Short-range order describes the degree of the chemical state with respect to the local arrangement of atoms, which can be partially preserved even when the LRO is completely lost [20,25].

In our work, the use of these parameters to study the ion-amorphization of SiC fibers is limited by two factors. First, the Si-C signal increases at low doses, hence invalidating $\mathrm{A} / \mathrm{A}_{\text {norm }}$ as an indicative of the total disorder evolution, and secondly, the enormous impact of the free $\mathrm{C}$ of the as-received fibers in their Raman spectra, hence invalidating $\chi_{(\mathrm{C}-\mathrm{C})}$ as a good indicative of the short-range order evolution. In order to overcome these limitations, chemical disorder has been calculated as the ratio of $\mathrm{Si}-\mathrm{Si}$ homonuclear bonds to $\mathrm{Si}-\mathrm{C}$ bonds $\left(\chi_{(\mathrm{Si}-\mathrm{Si})}\right)$ under the assumption that the intensity of the Raman peaks is proportional to the concentration of the related atomic bond [20].

Figure 7 shows the $\chi_{(\mathrm{Si}-\mathrm{Si})}$ evolution as a function of the dose for the three samples. Data has been fitted with a multistep damage accumulation (MSDA) model given by equation (2):

$$
f_{d}=\sum_{i=1}^{n}\left[\left(f_{d, i}^{s a t}-f_{d, i-1}^{s a t}\right)\left(1-e^{-\sigma_{i}\left(\varphi-\varphi_{i-1}\right)}\right)\right]
$$

where $n$ is the number of steps in damage accumulation, $f_{d, i}^{\text {sat }}$ the level of damage saturation for the step $i, \sigma_{1}$ the damage cross-section for the step $i$, and $\phi$ and $\phi_{i-1}$ the dose and the saturation dose of the ith step [26].

MSDA model assumes that damage accumulation is a sequence of distinct transformations of the current structure of the irradiated material and that reduces to a direct impact (DI) model meaning that amorphization is achieved in a single cascade [26]. Table 3 gathers the best-fit (non-linear least-squares Marquardt-Levenberg algorithm) parameters for $n=2$ of the $\chi_{(\mathrm{Si}-\mathrm{Si})}$ evolution with dose.

MSDA parameters for $6 \mathrm{H}-\mathrm{SiC}$ amorphization kinetics are consistent with previous reported ones based in RBS and $\mu \mathrm{RS}$ data $[25,27]$ hence confirming $\chi_{(\mathrm{Si}-\mathrm{Si})}$ as a relevant indicative for the amorphization level of the sample.

According to the MSDA parameters, there is a significant difference in the first stage of the amorphization process between $\mathrm{SiC}$ fibers and $6 \mathrm{H}-\mathrm{SiC}$. However, this difference may arise from the difficulty to treat the Raman spectra of $\mathrm{SiC}$ fibers due to their $\mathrm{C}$ signal so it cannot be directly attributed to a prompt amorphization. More experimental data is needed to confirm this hypothesis. 

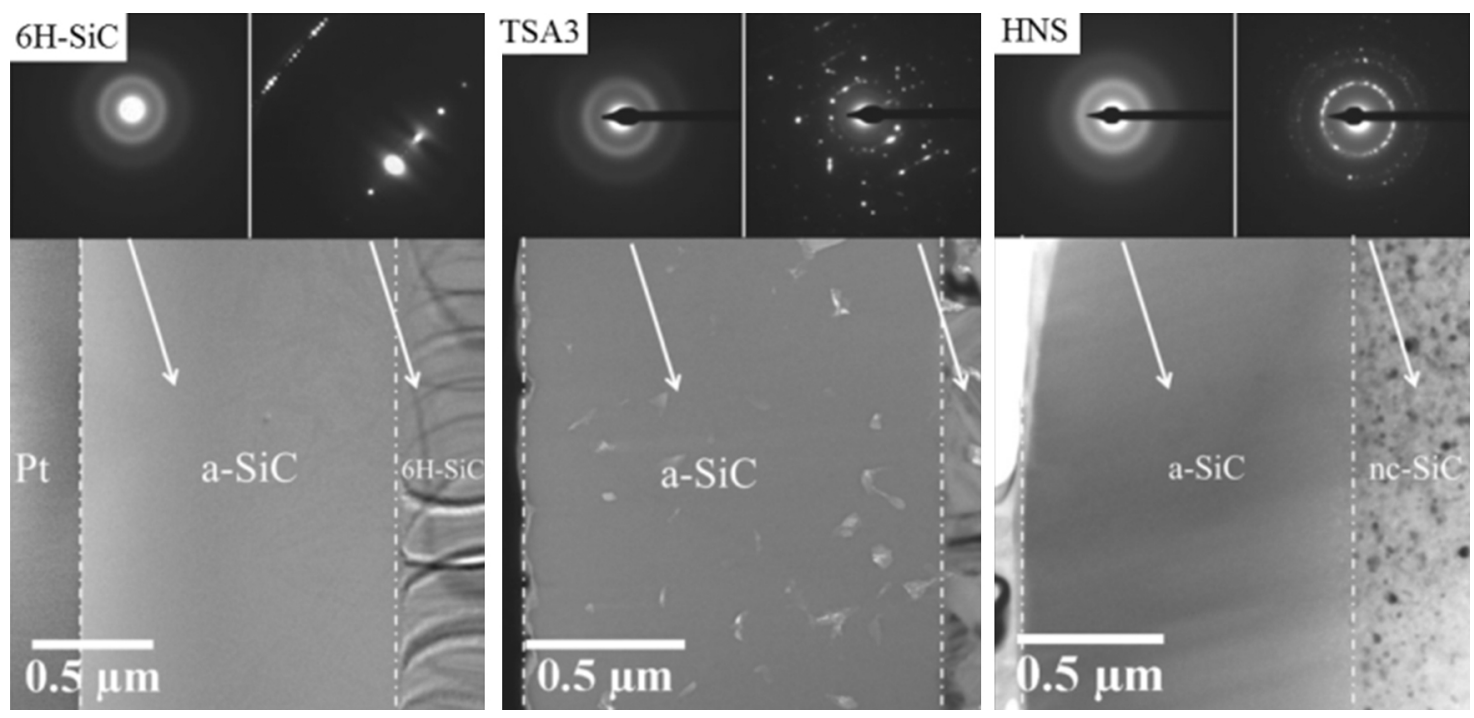

Fig. 6. TEM images and SAED patterns obtained from the irradiated $6 \mathrm{H}-\mathrm{SiC}$ and $\mathrm{SiC}$ fibers with $4 \mathrm{MeV} \mathrm{Au}^{3+}$ ions at RT to $2 \times 10^{15} \mathrm{~cm}^{-2}$. The concentric and diffuse rings in SAED patterns indicate that the irradiated layer is completely amorphous (a-SiC). nc-SiC: nanocrystalline $\mathrm{SiC}$ (adapted from Ref. [5]).

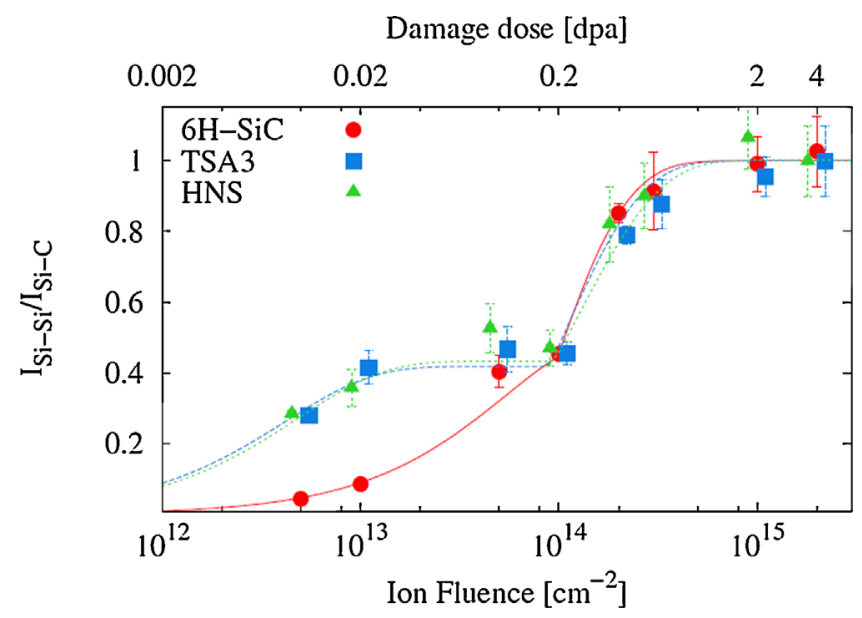

Fig. 7. Intensity of the Raman peaks associated to homonuclear $\mathrm{Si}-\mathrm{Si}$ bonds normalized to the intensity of the Raman peaks associated to $\mathrm{Si}-\mathrm{C}$ bonds. Experimental data is horizontally offset for the sake of clarity and fitted with the MSDA model $(n=2)$ presented in equation (2).

Table 3. Best-fit MSDA parameters for $n=2$ (two-step) of the $\chi_{(\mathrm{Si}-\mathrm{Si})}$ evolution with dose.

\begin{tabular}{llllll}
\hline Sample & \multicolumn{4}{c}{$n=2$} \\
\cline { 2 - 3 } & \multicolumn{2}{c}{$i=1$} & & \multicolumn{2}{c}{$i=2$} \\
\cline { 2 - 3 } \cline { 5 - 6 } & $f_{d}^{\text {sat }}$ & $\sigma_{1}{ }^{\mathrm{a}}$ & & $f_{d}^{\text {sat }}$ & $\sigma_{2}{ }^{\mathrm{a}}$ \\
\hline 6H-SiC & 0.58 & 0.54 & & 0.82 \\
TSA3 & 0.45 & 0.046 & & 1 & 0.94 \\
HNS & 0.46 & 0.049 & & 1 & 1.18 \\
\hline
\end{tabular}

${ }^{\mathrm{a}}$ Cross-sections in $\times 10^{-14} \mathrm{~cm}^{-2}$ units.
On the other hand, all irradiated samples show an inflexion point around $10^{14} \mathrm{~cm}^{-2}(0.2 \mathrm{dpa})$ and reach the saturation value over $3 \times 10^{14} \mathrm{~cm}^{-2}$ (0.6 dpa). Therefore, it can be asserted that the three samples present a two-step amorphization process regardless of their different polytype, composition and microstructure.

It is widely accepted that GBs act as point defect sinks [28]. However, the grain size must be optimized because a small grain size has two opposing effects on the free energy of an irradiated material. For instance, a smaller grain size hinders intragranular point defects accumulation which, in turn, decreases the free energy resulting from irradiation-induced defects. However, a smaller grain size also may increase the free energy resulting from the increase on the GB density which can favor the path toward an amorphous phase [29]. The microstructure influence of the behavior of $\mathrm{SiC}$ under irradiation is controversial as both experimental and computational studies can be found concerning whether grain refinement enhances or reduces $\mathrm{SiC}$ radiation resistance [30-33]. The similar ion-amorphization doses of $6 \mathrm{H}-\mathrm{SiC}$, TSA3 and HNS suggest that the microstructure of these fibers is not refined enough to show significant enhanced or reduced radiation resistance - not even for the HNS fibers which grain sizes are around $20 \mathrm{~nm}$.

\subsection{In situ E-SEM thermal annealing}

Radiation-induced amorphization is detrimental for the use of $\mathrm{SiC}$ under nuclear environments at low temperatures as it causes the degradation of the material's physico-chemical properties [34]. Even though amorphous $\mathrm{SiC}(\mathrm{a}-\mathrm{SiC})$ is known to be highly stable, irradiation-induced damage in $\mathrm{SiC}$ can be recovered and the a-SiC layer recrystallized by thermal annealing at high temperatures $[25,35]$. However, 


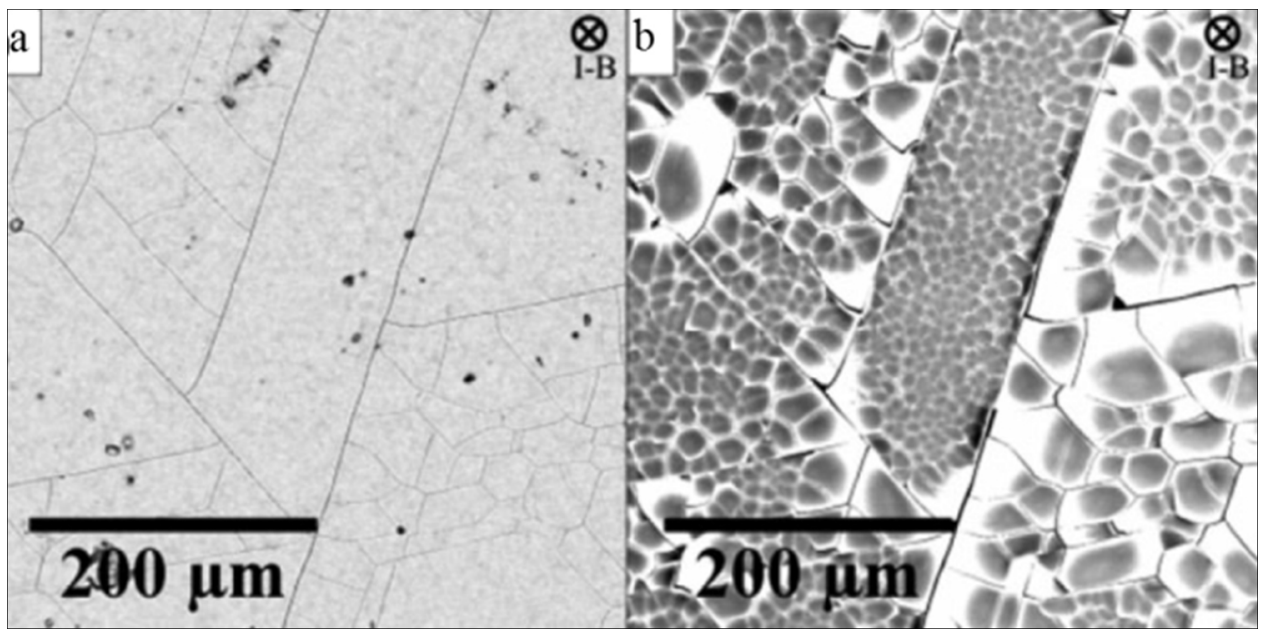

Fig. 8. Mechanical failure evolution of the $\mathrm{SiC}$ ion-amorphized layer during thermal annealing: (a) cracks appear along the cleavage planes and eventually lead to (b) exfoliation (adapted from Ref. [37]).

it has been reported that thermal annealing has an undesirable side effect. As shown in Figure 8, it induces mechanical failure of the ion-amorphized layers in single crystals $\mathrm{SiC}[25,36]$ and in HNS fibers [37]. However, little information concerning thermal annealing-induced mechanical failure is available for $\mathrm{SiC}$. It has been reported that thermal stresses - arising from a mismatch between the coefficient of thermal expansion of the irradiated layer and the pristine substrate - are not responsible for the mechanical failure [37] and recrystallization-related stresses have been pointed out as the cracking and delamination cause [36,37].

In order to provide further information on how recrystallization is related to mechanical failure, several thermal annealing tests on ion-amorphized $6 \mathrm{H}-\mathrm{SiC}$ single crystals have been conducted and observed at different temperature ramps via in situ E-SEM.

Figure 9 shows the evolution of the linear crack density as a function of time for different heating rates. As it can be observed, crack density reaches similar saturation values independently of the heating rate whereas cracking kinetics are heating rate-dependent. For instance, both the temperatures at which cracking is triggered and the crack density growth rate increase with increasing heating rates.

Cracking kinetics appears to be thermally activated phenomenon. In order to obtain the characteristic activation energy $\left(E_{\mathrm{a}}\right)$ of the process, the experimental data have been assumed to obey an Arrhenius law. For instance, Figure 10 shows the log-plot of two characteristic features of the cracking phenomenon: the inverse of the time necessary to reach the $50 \%$ of the cracking density $\left(t_{50 \%}\right)$ as a function of the inverse of the sample temperature at time $t_{50 \%}$, denoted as $T_{50 \%}$. These two parameters have been successfully applied for the study of the recrystallization temperature of tungsten as a function of the heating rate and allow to get rid of the time dependency of the test [38]. Linear fit to the log-plot yields an $E_{\mathrm{a}}$ of $1.05 \mathrm{eV}$. This value falls in the range of recrystallization activation energies

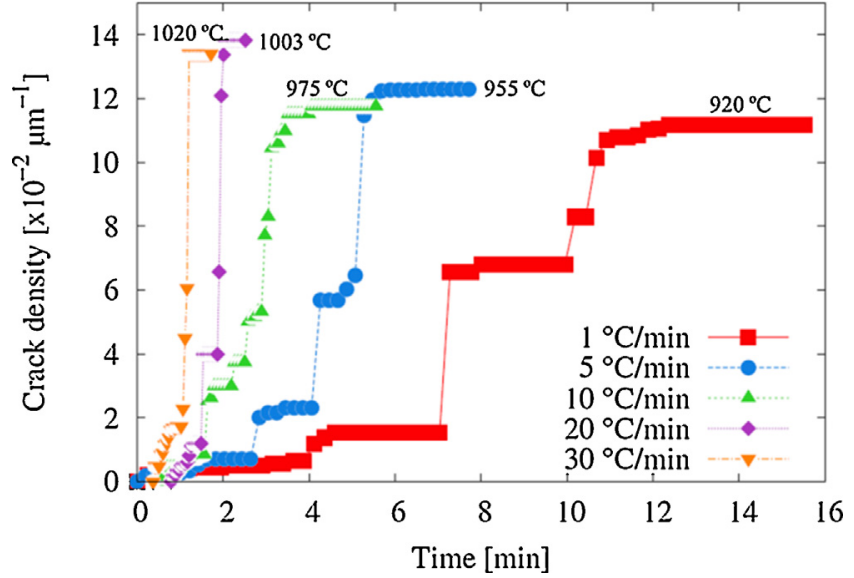

Fig. 9. Crack density evolution during the in situ thermal annealing for different temperature ramps. Values near the curves refer to the temperature at which the first crack was observed during the respective test.

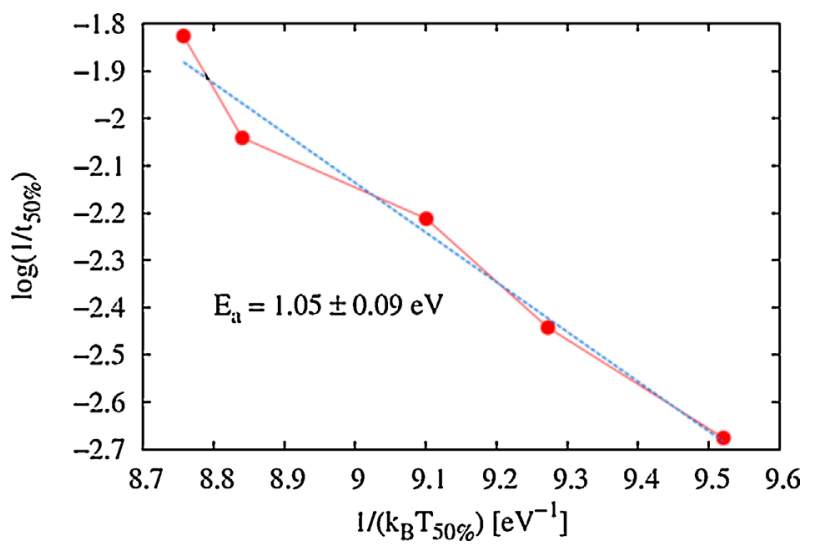

Fig. 10. Log-plot of the inverse of the time necessary to reach the $50 \%$ of the cracking density $\left(t_{50 \%}\right)$ as a function of the inverse of temperature at this moment $\left(T_{50 \%}\right) . E_{\mathrm{a}}$ is the activation energy for the cracking phenomenon. 
found by isothermal annealing of ion-amorphized $\mathrm{SiC}$, i.e. $0.36-0.65^{25}$ to $2.1^{36} \mathrm{eV}$, sustaining that recrystallizationrelated stresses are the underlying mechanism which induced mechanical failure.

\section{Conclusions}

In this work, ion-amorphization of $\mathrm{SiC}$ fibers has been studied in terms of surface $\mu \mathrm{RS}$ and TEM imaging and compared to the model material, i.e. $6 \mathrm{H}-\mathrm{SiC}$. It is reported that $\mathrm{SiC}$ fibers, HNS and TSA3, and $6 \mathrm{H}-\mathrm{SiC}$ display a similar ion-amorphization process despite their different $\mathrm{SiC}$ polytypes and microstructures. Critical amorphization dose yields $\sim 3 \times 10^{14} \mathrm{~cm}^{-2}(\sim 0.6 \mathrm{dpa})$ for $4 \mathrm{MeV}$ Au ions at RT.

Also, the kinetics of thermally annealing-induced cracking is studied via in situ E-SEM observations. It is reported that the temperatures at which the first cracks appear as well as the pace of crack density growth increase with increasing heating rates. The activation energy of the cracking process yields $1.05 \mathrm{eV}$ in agreement with recrystallization activation energies of ion-amorphized samples. This observation supports recrystallization as the stress source causing the mechanical failure of the annealed samples.

The authors would like to thank JANNUS staffs for their technical support during irradiations and EMIR network for funding the irradiation time. Also we are grateful to B. Arnal and D. Troadec for FIB sample preparation and T. Vandenberghe for TEM observations.

\section{Nomenclature}

$\mu \mathrm{RS} \quad$ micro-Raman Spectroscopy

CVI Chemical Vapor Infiltration

dpa displacements per atom

DTA Dose To Amorphization

E-SEM Environmental Scanning Electron Microscope

GB Grain Boundary

GENII Generation II (current nuclear reactors)

GFR Gas Fast Reactor

HNS Hi-Nicalon type $\mathrm{S}$

LFR Lead Fast Reactor

MSDA Multistep Damage Accumulation

MSR Molten Salt Reactor

RBS Rutherford Backscattering Spectrometry

SAED Selected Area Electron Diffraction

SCWR Super Critical Water Reactor

SFR Sodium Fast Reactor

TEM Transmission Electron Microscope

TSA3 Tyranno SA3

VHTR Very High Temperature Reactor

\section{References}

1. P. Yvon, F. Carré, Structural materials challenges for advanced reactor systems, J. Nucl. Mater. 385, 217 (2009)

2. S.J. Zinkle, J.T. Busby, Structural materials for fission \& fusion energy, Mater. Today 12, 12 (2009)
3. A. Iveković, S. Novak, G. Drazić, D. Blagoeva, S.G. de Vicente, Current status and prospects of $\mathrm{SiCf} / \mathrm{SiC}$ for fusion structural applications, J. Eur. Ceram. Soc. 33, 1577 (2013)

4. C.A. Schneider, W.S. Rasband, K.W. Eliceiri, NIH Image to ImageJ: 25 years of image analysis, Nat. Methods 9, 671 (2012)

5. J. Huguet-Garcia, A. Jankowiak, S. Miro, D. Gosset, Y. Serruys, J.-M. Costantini, Study of the Ion-irradiation behavior of advanced $\mathrm{SiC}$ fibers by Raman Spectroscopy and Transmission Electron Microscopy, J. Am. Ceram. Soc. 98, $675(2015)$

6. A.R. Bunsell, A. Piant, A review of the development of three generations of small diameter silicon carbide fibres, J. Mater. Sci. 41, 823 (2006)

7. C. Sauder, J. Lamon, Tensile creep behavior of SiC-based fibers with a low oxygen content, J. Am. Ceram. Soc. 90, 1146 (2007)

8. Y. Serruys, P. Trocellier, S. Miro, E. Bordas, M.O. Ruault, O. Kaïtasov, S. Henry, O. Leseigneur, T. Bonnaillie, S. Pellegrino, S. Vaubaillon, D. Uriot, JANNUS: a multiirradiation platform for experimental validation at the scale of the atomistic modelling, J. Nucl. Mater. 386-388, 967 (2009)

9. J.F. Ziegler, M.D. Ziegler, J.P. Biersack, SRIM-The stopping and range of ions in matter (2010), Nucl. Instrum. Methods Phys. Res. B 268, 1818 (2010)

10. R. Devanathan, W.J. Weber, F. Gao, Atomic scale simulation of defect production in irradiated 3C-SiC, J. Appl. Phys. 90, 2303 (2001)

11. R. Podor, D. Pailhon, J. Ravaux, H.-P. Brau, Development of an integrated thermocouple for the accurate sample temperature measurement during high temperature Environmental Scanning Electron Microscope (HT-ESEM) experiments, Microscopy and Microanalysis 21, 307 (2015)

12. F. Bechstedt, P. Käckell, A. Zywietz, K. Karch, B. Adolph, K. Tenelsen, J. Furthmüller, Polytypism and properties of silicon carbide, Phys. Status Solidi 202, 35 (1997)

13. P. Colomban, G. Gouadec, L. Mazerolles, Raman analysis of materials corrosion: the example of $\mathrm{SiC}$ fibers, Mater. Corros. 53, $306(2002)$

14. G. Gouadec, P. Colomban, Raman Spectroscopy of nanomaterials: how spectra relate to disorder, particle size and mechanical properties, Prog. Cryst. Growth Charact. Mater. 53, 1 (2007)

15. M. Havel, P. Colomban, Raman and Rayleigh mapping of corrosion and mechanical aging in SiC fibres, Compos. Sci. Technol. 65, 353 (2005)

16. S. Nakashima, H. Harima, Raman investigation of $\mathrm{SiC}$ polytypes, Phys. Status Solidi 162, 39 (1997)

17. L.G. Cançado, K. Takai, T. Enoki, M. Endo, Y.A. Kim, H. Mizusaki, A. Jorio, L.N. Coelho, R. Magalhães-Paniago, M.A. Pimenta, General equation for the determination of the crystallite size L[sub a] of nanographite by Raman spectroscopy, Appl. Phys. Lett. 88, 163106 (2006)

18. S. Zinkle, Radiation-induced effects on microstructure, Compr. Nucl. Mater. 1, 65 (2012)

19. G.S. Was, R.S. Averback, Radiation damage using ion beams, Compr. Nucl. Mater. 1, 195 (2012)

20. S. Sorieul, J.-M. Costantini, L. Gosmain, L. Thomé, J.-J. Grob, Raman spectroscopy study of heavy-ion-irradiated $\alpha$-SiC, J. Phys.: Condens. Matter 18, 5235 (2006)

21. W. Bolse, Formation and development of disordered networks in Si-based ceramics under ion bombardment, Nucl. Instrum. Methods Phys. Res. B 141, 133 (1998) 
22. M. Ishimaru, A. Hirata, M. Naito, I.-T. Bae, Y. Zhang, W.J. Weber, Direct observations of thermally induced structural changes in amorphous silicon carbide, J. Appl. Phys. 104, 033503 (2008)

23. M. Ishimaru, I.-T. Bae, Y. Hirotsu, S. Matsumura, K.E. Sickafus, Structural relaxation of amorphous silicon carbide, Phys. Rev. Lett. 89, 055502 (2002)

24. F. Linez, A. Canizares, A. Gentils, G. Guimbretiere, P. Simon, M.-F. Barthe, Determination of the disorder profile in an ionimplanted silicon carbide single crystal by Raman spectroscopy, J. Raman Spectrosc. 43, 939 (2012)

25. S. Miro, J.-M. Costantini, J. Huguet-Garcia, L. Thomé, Recrystallization of hexagonal silicon carbide after gold ion irradiation and thermal annealing, Philos. Mag. 94, 3898 (2014)

26. J. Jagielski, L. Thomé, Damage accumulation in ionirradiated ceramics, Vacuum 81, 1352 (2007)

27. X. Kerbiriou, J.-M. Costantini, M. Sauzay, S. Sorieul, L. Thomé, J. Jagielski, J.-J. Grob, Amorphization and dynamic annealing of hexagonal $\mathrm{SiC}$ upon heavy-ion irradiation: effects on swelling and mechanical properties, J. Appl. Phys. 105, 073513 (2009)

28. W.G. Wolfer, Fundamental properties of defects in metals, Compr. Nucl. Mater. 1, 1 (2012)

29. T.D. Shen, Radiation tolerance in a nanostructure: is smaller better?, Nucl. Instrum. Methods Phys. Res. B 266, 921 (2008)

30. W. Jiang, H. Wang, I. Kim, I.-T. Bae, G. Li, P. Nachimuthu, Z. Zhu, Y. Zhang, W. Weber, Response of nanocrystalline 3C silicon carbide to heavy-ion irradiation, Phys. Rev. B 80, 161301 (2009)
31. W. Jiang, H. Wang, I. Kim, Y. Zhang, W.J. Weberb, Amorphization of nanocrystalline $3 \mathrm{C}-\mathrm{SiC}$ irradiated with $\mathrm{Si}$ ions, J. Mater. Res. 25, 2341 (2010)

32. L. Jamison, P. Xu, K. Sridharan, T. Allen, Radiation resistance of nanocrystalline silicon carbide, in Advances in materials science for environmental and nuclear technology II: ceramic transactions, edited by S.K. Sundaram, K. Fox, T. Ohji, E. Hoffman (John Wiley \& Sons, Inc., Hoboken, NJ, USA, 2011), Vol. 227

33. L. Jamison, M.-J. Zheng, S. Shannon, T. Allen, D. Morgan, I. Szlufarska, Experimental and ab initio study of enhanced resistance to amorphization of nanocrystalline silicon carbide under electron irradiation, J. Nucl. Mater. 445, 181 (2014)

34. Y. Katoh, L.L. Snead, I. Szlufarska, W.J. Weber, Radiation effects in $\mathrm{SiC}$ for nuclear structural applications, Curr. Opin. Solid State Mater. Sci. 16, 143 (2012)

35. S. Miro, J.-M. Costantini, S. Sorieul, L. Gosmain, L. Thomé, Recrystallization of amorphous ion-implanted silicon carbide after thermal annealing, Philos. Mag. Lett. 92, 633 (2012)

36. A. Höfgen, V. Heera, F. Eichhorn, W. Skorupa, Annealing and recrystallization of amorphous silicon carbide produced by ion implantation, J. Appl. Phys. 84, 4769 (1998)

37. J. Huguet-Garcia, A. Jankowiak, S. Miro, R. Podor, E. Meslin, Y. Serruys, J.-M. Costantini, In situ E-SEM and TEM observations of the thermal annealing effects on ionamorphized 6H-SiC single crystals and nanophased $\mathrm{SiC}$ fibers, Phys. Status Solidi 252, 149 (2015)

38. C.J.M. Denissen, J. Liebe, M. van Rijswick, Recrystallisation temperature of tungsten as a function of the heating ramp, Int. J. Refract. Met. Hard Mater. 24, 321 (2006)

Cite this article as: Juan Huguet-Garcia, Aurélien Jankowiak, Sandrine Miro, Renaud Podor, Estelle Meslin, Lionel Thomé, Yves Serruys, Jean-Marc Costantini, Characterization of the ion-amorphization process and thermal annealing on third generation SiC fibers and 6H-SiC, EPJ Nuclear Sci. Technol. 1, 8 (2015) 